\title{
O PRINCÍPIO RESPONSABILIDADE DE HANS JONAS E A TELEOLOGIA OBJETIVA DOS VALORES
}

\author{
José N. Heck \\ Universidade Federal de Goiás
}

\begin{abstract}
Jonas's ethics of the future does not substitute traditional ethical doctrines. Rather, it is a response to the new challenge of responsibility towards the technological civilization. Hans Jonas focuses on the relevance of the significance of empirical knowledge for ethics directed towards the future of humanity. An eco-ethics of integrating intent must deal with complex situations, burdened with costs, risks and uncertainties of an ecological, economic, juridical, political and/or social origin. Jonas's principle counts on the skepticism of culture faced with scientific progress and the technological application of knowledge.
\end{abstract}

Keywords: Ethics, principle, environment, responsibility, values.

Resumo: A ética jonasiana do futuro não substitui as doutrinas éticas tradicionais. Trata-se de atender ao novo desafio da responsabilidade para com a civilização tecnológica. Hans Jonas acentua a relevância do significado do saber empírico para a ética direcionada ao futuro da humanidade. Uma ecoética com pretensão integradora deve lidar com situações complexas, oneradas por custos, riscos e incertezas de proveniência ecológica, econômica, jurídica, política e/ou social. 0 princípio de Jonas pode contar com o ceticismo da cultura frente ao progresso das ciências e da aplicação tecnológica do conhecimento.

Palavras-Chave: Ética, princípio, meio ambiente, responsabilidade, valores.

\section{Introdução}

A avaliação filosófica da herança intelectual de Hans Jonas (19031993) pode ser rastreada sob o pano de fundo de três critérios: o amparo da história, a herança cristã e as ferramentas metafísicas. 
A abordagem histórica confronta, avalia e enaltece o enfrentamento do filósofo alemão com dois clássicos da Modernidade: o empirista Francis Bacon (1561-1626) e o racionalista René Descartes (1596-1650), respectivamente ${ }^{1}$. Cada um dos dois pensadores situa-se na raiz do Iluminismo, ambos são pioneiros do credo científico e avaliam positiva e responsavelmente o futuro do conhecimento de sua época. De acordo com o Novum Organum (1620), Bacon formula todo altaneiro, ao escrever: "Trataremos agora das causas dos erros e de sua persistência que se prolongou por séculos. Estas são muitas e muito poderosas. Em vista disso, não há motivos para se admirar de que tenham escapado e tenham permanecido ocultas dos homens as coisas que vão agora ser expostas"2. Por sua vez, no Discours de la Méthode (1637), Descartes registra que, ao haver adquirido algumas noções gerais relativas à Física, imediatamente começou a comprová-las "e que, em vez dessa filosofia especulativa que se ensina nas escolas, pode-se encontrar uma outra prática (...) e assim nos tornar como que senhores e possuidores da natureza"3.

A doutrina teológico-cristã repercute em Jonas como reação à ausência do sentimento de responsabilidade na ética categórica de tradição kantiana. Já em Rudolf Otto (1860-1937) trata-se de transcendentalizar as relações sócio-empíricas dos seres humanos em nome da fé e esperança cristãs ${ }^{4}$. De forma mais clara se posiciona o pastor Albert Schweitzer (1875-1965) contra o moralismo racionalista na esteira de Immanuel Kant (1724-1804)5. De maneira ainda mais radical argumenta o teólogo Dieter Bonhoeffer (19061945) - executado pelo nazismo - ao combater o isolamento, a privatização do indivíduo para insistir sobre a necessidade de zelar pela responsabilidade em relação ao próximo, ou seja, "a norma da ação não é um genérico

\footnotetext{
1 GIACOIA Jr., O. "Um Direito próprio da Natureza? Notas sobre Ética, Direito e Tecnologia". In Fragmentos de Cultura, Goiânia, v. 14, n. 4, 2004, p. 637-654.

2 BACON, F. Novum Organum sive indica vera de interpretatione naturae. In: The Latin Library, http://www.thelatinlibrary.com/bacon.html. "Jam vero veniendum ad causas errorum, et tam diuturnae in illis per tot secula morae quae plurimae sunt et potentissimae: ut tollatur omnis admiratio, haec quae adducimus homines hucusque latuisse et fugisse".

3 DESCARTES, R. Discours de la méthode. Hamburg: F. Meiner (Französisch - Deutsch), 1990, p. 100. "(...) et qu'au lieu de cette philosophie spéculative, qu'on enseigne dans les écoles, on en peut trouver une pratique (...) et ainsi nous rendre comme maîtres et possesseurs de la nature".

${ }^{4}$ OTTO, R. "Das Gefühl der Verantwortlichkeit". In: Aufsätze zur Ethik. Hg. Jack Stewart Boozer. München 1981, p. 143-174.

${ }^{5}$ SCHWEITZER, A. Kultur und Ethik. Kulturphilosophie, 6. Aufl., München, 1947.
} 
princípio em vigor, mas o próximo concreto, assim como ele me é dado por Deus"6.

O caráter metafísico da responsabilidade assegura que os critérios da mesma não resultam da consciência individual, mas são adquiridos de uma esfera anterior ao sujeito. O portador de responsabilidade só pode ser tomado por responsável devido a um determinado evento, uma vez que tal acontecimento remete do interior de si mesmo ao respectivo portador. "A responsabilidade não é”, segundo Georg Picht (1913-1982), "assunto de consciência moral, mas encontra-se pré-figurada na estrutura do acontecimento" . Picht entende que a crescente complexidade da vida moderna requer transferência do conceito de responsabilidade para processos carentes de subjetividade, ou seja, trata-se de uma organização coletiva de responsabilidade que "não surja da vontade do sujeito, mas se origina cada vez da forma específica segundo as tarefas a serem resolvidas" forma que, de um lado, corteja a complexidade sistêmica da sociedade moderna com o discurso da responsabilidade, Picht desvia a praxe discursiva e destina a responsabilidade à existência escatológica da metafísica, quer dizer, somos "responsáveis por tudo o que acontece em conexão com determinados homens ou coisas" .

A metafísica pichtiana se mantém insensível à tradição filosófica da ética. Para Jonas, ao contrário, a disciplina da ética e o universo dos valores só podem ser fundamentados com recursos metafísicos.

\section{A responsabilidade $\mathrm{e} 0$ ethos do futuro}

O Princípio Responsabilidade: ensaio de uma ética para a civilização tecnológica (1979) constitui a Bíblia da primeira geração tecnológica insatisfeita do pós-guerra. Expressões como "direito ao não-saber" (Recht

\footnotetext{
${ }^{6}$ BONHOEFFER, D. Ethik. Hg. Ilse Tödt, Heinz Eduard, Ernst Feil und Clifford Green. München, 1992, p. 220. "Die Norm des Handelns ist nicht ein allgemeingültiges Prinzip, sondern der konkrete Nächste, wie er mir von Gott gegeben ist".

7 PICHT, G. "Der Begriff der Verantwortung". In: Wahrheit, Vernunft, Verantwortung. Philosophische Studien. Stuttgart, 1969, p. 320.

${ }^{8}$ Ibidem, p. 339. (...) die "nicht aus dem Willen des Subjektes, sondern aus der spezifischen Form der je zu lösenden Aufgaben".

${ }^{9} \mathrm{Ibidem}$, p. 337. "(...) man ist verantwortlich für alles, was im Zusammenhang mit bestimmten Menschen oder Sachen geschieht".
} 
zum Nichtwissen) e "heurística do temor" (Heuristik der Furcht) identificam uma era e repercutem ainda em publicações éticas de peso na virada do milênio, quando Jürgen Habermas (1929-), em O Futuro da Natureza Humana (2001), remete a Jonas ao escrever: "O ato técnico tem a forma da intervenção, não da construção"10.

Dentre as várias frentes visualizadas na obra jonasiana destaca-se a distância crescente entre o agente tecnológico e seus produtos, bem como, ao longo prazo, a incerteza das consequências dos mesmos na civilização técnico-científica. Jonas distancia-se ostensivamente de Kant. Considera a moral do filósofo de Königsberg ultrapassada, devido ao círculo relativamente restrito de interações humanas que o imperativo categórico busca pretensamente abarcar. Assim, relata Jonas, não há registro na moral de Kant de deveres a serem cumpridos aos membros de gerações futuras ou de uma obrigação por parte dos humanos para com a natureza não-humana. Tais handicaps normativos levam Jonas a não se satisfazer com meras correções pontuais do kantismo. O resultado é que a razão prática kantiana acaba convertida, por Jonas, em uma frente ética sui-generis, comprometida com o futuro das espécies e, à revelia de normatividade, amparada à moda aristotélica pela metafísica do ser. Jonas entende que a futura existência da humanidade não será assegurada pela moral e pela ética, mas a teremos devido à "metafísica como uma doutrina do ser, do qual a idéia do homem é uma parte"11.

A novidade de $O$ Princípio Responsabilidade está, em relação à ética kantiana, numa teleologia objetiva de valores, apta a ampliar a dimensão temporal da ética tradicional, limitada ao presente. Jonas está convencido de que uma ética do futuro, como avalista do bem-estar das gerações do amanhã, pode "somente ser fundamentada metafisicamente" 12 . O imperativo dessa nova bandeira normativa prescreve: "Age de modo que as consequências de tuas ações sejam compatíveis com a permanência da

10 Cf. HABERMAS, J. Die Zukunft der menschlichen Natur. Auf dem Weg zu einer liberalen Eugenik? Frankfurt a/Main: Suhrkamp, 2001, p. 84, ao citar Jonas: "Der technische Akt hat die Form der Intervention, nicht des Bauens". Cf. nota 16 infra.

11 JONAS, H. Das Prinzip Verantwortung. Versuch einer Ethik für die technologische Zivilisation. Frankfurt a/Main: Suhrkamp, 1979, p. 91. "(...) Metaphysik als einer Lehre vom Sein, wovon die Idee des Menschen ein Teil" ist.

12 Ibidem, p. 35. "(N)ur metaphysisch zu begründen". 
verdadeira vida humana sobre a Terra"13. A temporalização da moral, resultante do aumento de poder tecnológico-científico, tem por consequência o "dever para com a existência da humanidade futura"14, cujo princípio básico consiste, segundo Jonas, numa responsabilidade não-recíproca do homem com o mundo natural, contrariamente ao cuidado que os pais têm para com a prole.

Jonas assume a determinação das obrigações categóricas de Kant, não sem primeiro assentá-las sobre uma plataforma ontológica. Com isso, a futura existência da humanidade não está assegurada pelo mandamento do respeito moral, mas permanece ancorada na figura antropológica, vale dizer, não mais assume posições normativas, mas integra a ética numa doutrina do ser da qual a idéia de homem faz parte.

Em consequência, no âmbito da eugenia, as condições mais propícias à reprodução implicam intervenção, não o melhoramento genético da espécie humana ${ }^{15}$. O lastro metafísico da idéia de humanidade tem sua continuidade consequente numa teoria teleológica de ação, na qual propósitos subjetivos repousam sobre uma objetividade de fins, contidos na natureza como valores imanentes a ela e, portanto, previstos por ela própria. O bem moral configura-se, segundo Jonas, enquanto valor nas coisas mesmas, cujo objetivo "ser-que-tem-que-ser" postula a sua realização. Em suma, não é a lei moral que prescreve ações a uma vontade individual, mas, sim, é o caráter valorativo do ser que afeta nosso sentimento moral e lança, cada vez, o fundamento de condutas responsáveis. Radicalmente comprometido com o futuro da humanidade, $O$ Princípio Responsabilidade pode ser lido enquanto doutrina de uma ética de emergência para o futuro da espécie. $\mathrm{Na}$ ausência dela, "o reverso do poder atual", apostrofa Jonas, "é a servidão posterior dos vivos em relação aos mortos"16. Na coletânea Técnica, Medicina e Ética: para a Práxis do Princípio Responsabilidade (1987), o autor fala já em "ética da prevenção", na defesa radical contra o "mal exterior", objetivado pela

13 Ibidem, p. 36. "Handle so, dass die Wirkungen deiner Handlungen verträglich sind mit der Permanenz echten menschlichen Lebens auf Erden".

14 Ibidem, p. 85. "(...) Pflicht zum Dasein künftiger Menschheit".

15 JONAS. Technik, Medizin und Eugenik. Frankfurt a/Main: Insel Verlag, 1985, p. 165: "(...) Der technische Akt hat die Form der Intervention, nicht des Bauens".

${ }^{16} \mathrm{Ibidem}$, p. 168. "Die Kehrseite heutiger Macht ist die spätere Knechtschaft gegenüber Toten". 
deterioração da biosfera terrestre e in extremis pelo suicídio da espécie humana ${ }^{17}$.

A ética jonasiana do futuro não pretende substituir as doutrinas éticas usuais. Trata-se, a rigor, tão-só de complementar as diversas éticas tradicionais para atender ao novo desafio do superdimensionamento da civilização tecnológica. O caráter de complemento, atribuído à ética do ambiente, isenta Jonas de posicionar-se frente à colisão de deveres, de modo que sua proposta acaba ficando pelo meio. A tarefa típica de uma macroética de porte global não está presa a extremos, vale dizer, não pode limitar-se a tomar decisões isoladas que tenham consequências binárias, isto é, ou são irrelevantes ou fatais para as condições climáticas do planeta, à saúde da população, às liberdades civis do cidadão, e assim por diante. Uma ecoética com pretensão integradora deve lidar com situações complexas, oneradas por custos, riscos e incertezas de proveniência ecológica, econômica, jurídica, política e/ou social.

Não está claro, assim, se O Princípio Responsabilidade, após um longo processo ponderativo, pretende assegurar a sobrevivência nua e crua da humanidade em detrimento da liberdade, justiça e participação dos cidadãos na vida pública, itens considerados como formas consagradas de qualidade de vida pela tradição iluminista. Jonas fica devendo resposta à pergunta que visa estabelecer o grau de limitação tolerável numa situação de perigo, quando as liberdades individuais corram o risco de ficarem indistintas da subserviência, hipocrisia e mediocridades coletivas.

\section{In dubio pro malo ou a ameaça apocalíptica}

No âmbito da aplicação de Princípio da Responsabilidade Jonas acentua a relevância do significado do saber empírico para uma ética voltada ao futuro da humanidade. Com vistas à ampliação crescente do descomunal poder técnico-científico de interferir na natureza, conjugado a longo prazo, com o desconhecimento paralelo das consequências resultantes das ações humanas, Jonas postula a "aquisição da representação dos efeitos tardios

17 Ibidem, 209. 
como dever primordial da ética do futuro"18. Como também o mais acurado prognóstico é falho e a avaliação mais cuidadosa permanece insegura, o filósofo da responsabilidade propõe como regra de decisão o dito in dubio pro malo para lidar adequadamente com incertezas e fatores imponderáveis em questões ambientais; “(...) em caso de dúvida”, prescreve Jonas, “dá ouvidos à pior prognose antes de preferir a melhor, pois os lances tornaramse muito onerosos para o jogo" 19 .

Tal mote é, obviamente, tão-só aplicável, no caso de haver riscos de extrema gravidade, quando a hipótese do pior deve ser levada em conta como uma das alternativas viáveis. Em tal quadro, a eventualidade de o pior poder ocorrer, ainda que remotamente, exclui o apelo paliativo de que, numa civilização tecnológica, é comum tolerar efeitos negativos residuais. Mas, afora tal demarcação restritiva, seria um despropósito partir sempre e em qualquer constelação técnico-científica da prognose mais sombria, desfavorável e negativa. De resto, o critério jonasiano in dubio pro malo somente inspira confiança, quando estamos em condição de saber que o fato de assumir novos riscos não equivale à mera compensação de riscos atuais, ou seja, trata-se de averiguar quando inovações tecnológicas abrem, de fato, perspectivas de ação e possibilitam novas intervenções para o homem, não substituindo mui simplesmente técnicas há tempo em uso, e não menos perniciosas para a natureza do que as propostas de futuro em pauta.

O critério "na dúvida, a favor do pior" só é conversível em princípio e, enquanto tal, tão-só dá sustentação à tese genérica do conservacionismo, quando se atribui ao desenvolvimento técnico-científico uma unilateralidade progressiva, de modo que cada passo dado em frente, na fronteira tecnológica, soma invariavelmente uma porção a mais de perigos ao status quo de risco já existente. $\mathrm{Na}$ medida em que o filósofo da responsabilidade ética segue a tendência de predicar ao dinamismo técnico uma rota acentuadamente unidimensional, cujos caracteres nocivos levarão a humanidade ao desfecho apocalíptico, a questão metafísica instala-se no

18 JONAS. Das Prinzip Verantwortung. Versuch einer Ethik für die technologische Zivilisation. Frankfurt a/Main: Suhrkamp, 1979, p. 74. "Beschaffung der Vorstellung von den Fernwirkungen" als "erste Pflicht der Zukunftsethik".

${ }_{19}$ Idem. Technik, Medizin und Ethik. Zur Praxis des Prinzips Verantwortung. Frankfurt a/Main: Insel Verlag, 1985, p. 67. "(...) wenn im Zweifel, gib der schlimmeren Prognose vor der besseren Gehör, denn die Einsätze sind zu gross geworden für das Spiel". 
cerne da ética, "qual seja, se e por que deve haver uma humanidade (...); sim, porque, em geral, deve haver vida" 20 .

Convertido em princípio, o critério in dubio pro malo devolve ao senhorio metafísico da natureza o caráter ético da conduta humana. "Se existir é um imperativo categórico para a humanidade”, apostrofa Jonas, "então todo jogo suicida com essa existência está categoricamente proibido, e ousadias técnicas, nas quais esta é a aposta, ainda que apenas remotíssima, devem ficar excluídas ab initio"21.

Jonas sustenta a ética metafísica, por meio do realismo moral. A validade de juízos morais realistas se lhe afigura objetiva, à revelia das conviç̧ões as quais assistem aos sujeitos que ajuízam acerca de bom e mau. A peculiaridade do realismo moral jonasiano consiste numa combinação solta entre naturalismo ético e intuicionismo ético. Enquanto este mantém insights morais à distância de ocorrências empírico-naturais, aquele recepciona conhecimentos morais de acordo com modelos naturais que, embora alegados como fatos, permanecem isentos de objetivações empíricas.

Sob o pano de fundo de uma filosofia da natureza que conjuga fenomenologia e neoaristotelismo, Jonas sustenta, já em Organismo e liberdade (1973), uma fundamentação naturalista para moral sem, contudo, lastrar a base natural com elementos empíricos. "A separação do reino 'objetivo' e 'subjetivo' (...)", constata o autor, "é o destino moderno. Sua reunificação pode (...) tão-somente ser providenciada pelo lado 'objetivo', (...) por meio de uma revisão da idéia de natureza"22. Jonas admite, como realista, que a destinação do homem poderia talvez ser flagrada, graças à evolução, na auto-realização humana qua pessoa no ponto terminal da substância evolutiva originária. Apoiado sobre tal hipótese, "seria possível conceber um princípio ético que não repousasse sobre a autonomia do Eu e tampouco resultasse de demandas sociais, mas fosse”, segundo o filósofo alemão,

${ }^{20}$ Cf. JONAS. "Por que a técnica moderna é um objeto para a ética". Tradução Oswaldo Giacoia Jr. In: Natureza Humana: Revista Internacional de Filosofia e Práticas Psicoterápicas. São Paulo, v. 1, n. 2, p. 407-420, 1999 (a citação encontra-se na p. 414).

21 Ibidem.

22 JONAS. Organismus und Freiheit: Ansätze zu einer philosophischen Biologie. Göttingen, 1973, p. 341. "Die Scheidung des 'objektiven' und des 'subjektiven' Reiches (...) ist das moderne Schicksal. Ihre Wiedervereinigung kann (...) nur von der 'objektiven' Seite her bewerkstelligt werden; (...) duch eine Revision der Idee der Natur". 
"devedor a uma destinação objetiva, por parte da natureza em seu todo (o que a teologia costumava designar de ordo creationis (...)"23.

A planilha original do naturalismo, Jonas a irá executar apenas parcialmente, à moda negativa. A lógica defensiva, inerente a uma ética de prevenção, bloqueia a construção de uma ordem natural positiva de valores. $\mathrm{Na}$ contramão de um realismo moral, cuja articulação universal abrangesse objetivamente a natureza animada e inanimada, Jonas se satisfaz em sedimentar um dever irrestrito em relação à preservação da humanidade, uma vez que lhe parece suficientemente demonstrado que os fins dos seres naturais culminam, em sua totalidade, no ser humano. A tentativa jonasiana de fundamentar um imperativo categórico em favor da natureza animada é executada em três etapas: a) existe uma finalidade natural intrínseca, cuja objetividade independe de interpretações acerca da natureza; b) a finalidade objetiva da natureza constitui um bem em si; e, c) do telos, como bem intrínseco, deriva a obrigação categórica de sua incondicional preservação ${ }^{24}$.

Jonas reforça argumentos naturalistas com elementos intuitivos; assim, a teleologia é ilustrada pela ética do ser com o modo como uma criança recém-nascida é percebida, aceita e acolhida pelo entorno humano. O filósofo alemão constata que basta dirigir um olhar ao bebê $\hat{k}^{25}$ para intuitiva, imediata e espontaneamente saber que este ser necessita de cuidados especiais em seu desamparo. O exemplo baby serve a Jonas como "paradigma ôntico" 26 para evidenciar a claridade cristalina que unifica ser e valor. Para Jonas, feita uma vez a experiência do ser, enquanto valor do recém-nascido, o dogma ontológico da separação entre ser e dever-ser fica falsificado ${ }^{27}$.

O amparo objetivista, dado à moral pelo filósofo, acompanha sua tríplice interpretação do conceito de responsabilidade: Jonas aloca a instância de responsabilidade para dentro do objeto da responsabilidade, ou seja, são os próprios objetos que, com sua materialidade axiológica, nos chamam a uma responsabilização maior; Jonas concebe a responsabilidade moral como

\footnotetext{
${ }^{23}$ Ibidem. "Von daher würde sich ein Prinzip der Ethik ergeben, das letztlich weder in der Autonomie des Selbst noch in den Bedürfnissen der Gesellschaft begründet wäre, sondern in einer objektiven Zuteilung seitens der Natur des Ganzen (was die Theologie als ordo creationis zu bezeichnen pflegte)".

24 JONAS. Das Prinzip Verantwortung. Versuch einer Ethik für die technologische Zivilisation. Frankfurt a/Main: Suhrkamp, 1979, p. 135s.

$25 \mathrm{Ibidem}$, p. 235. "Sieh hin und du weisst".

26 Ibidem. "(O)ntisches Paradigma".

27 Ibidem. "(O)ntologisches Dogma".
} 
uma relação estritamente assimétrica, isenta de reciprocidade. "Responsabilidade, escreve ele, é o cuidado que se tem por dever para com algum outro ser que, uma vez ameaçado, faz com que o cuidado se converta em preocupação diligente" 28 . Jonas assume a responsabilidade retrospectiva como predicação normativamente neutra, com caráter meramente causal, reservando o distintivo da plenitude normativa à responsabilidade prospectiva, comprometida com aquilo que está por ser feito ${ }^{29}$, à moda da distinção arendtiana entre responsabilidade política pelo apoio dado à banalidade do mal e a responsabilidade culposa pelo mal praticado por ações ou omissões efetivas.

Sob o pano de fundo da concepção aristotélica de natureza, Jonas consegue demarcar, sem meio-termo, os limites entre normal/anormal, intervenção terapêutica/não-terapêutica, eugenia negativa/positiva, e assim por diante. Suas posições contundentes, ao longo dos anos, sobre complexos ético-científicos, desafios bioéticos e problemas da ética biomédica, como direito para morrer, morte cerebral, terapias genéticas e clonagem repercutem até ao presente. Enquanto atores coletivos neutralizam paulatinamente o princípio jonasiano de responsabilidade, indivíduos responsáveis que intermedeiam interesses esclarecidos, racionalidade moral e critérios de justiça com solidariedade, senso de cuidado, empatia e amizade continuam tendo nos textos do filósofo alemão um referencial ético intacto em sabedoria, pleno de retidão moral e recheado de coragem intelectual.

Quem age de maneira responsável não tem apenas em vista o outro em geral, mas sobremodo outros de modo especial. Na contramão à universalidade do correto e do justo, a consciência de responsabilidade abarca agentes que promovem a confiança, o altruísmo, o bem-estar e a felicidade, vale dizer, zelam pelo apreço, a diligência e o cuidado que pessoas virtuosas dedicam umas às outras.

O apelo incontido por mais e mais responsabilidade tem por aliado, na era da técnica, o ceticismo da cultura frente ao progresso das ciências e da aplicação tecnológica do conhecimento. A origem da crítica comum que, por um lado, causa a deferência metafísica de Jonas ao princípio da respon-

28 Ibidem, p. 391. "Verantwortung ist die als Pflicht anerkannte Sorge um ein anderes Sein, die bei Bedrohung seiner Verletzlichkeit zur 'Besorgnis' wird".

29 Ibidem, p. 174. "Verantwortung für Zu-Tuendes". 
sabilidade, alimenta de maneira substancial, por outro, a crítica antimetafísica ao conceito de responsabilidade. De acordo com a segunda vertente, postular responsabilidades faz sentido onde consequências do agir continuam imputáveis a pessoas que atuam como agentes, graças a apelos normativos. Quem, ao contrário, veicula o termo responsabilidade de maneira essencialmente genérica, isento de qualquer tipo de efeito gerado por fontes impessoais e coletivas, descaracteriza não apenas o conceito de responsabilidade, mas contribui também para a apatia moral. "O conceito de responsabilidade somente adquire um sentido preciso", escreve Arnold Gehlen (1904-1976), sociólogo alemão, "onde as consequências da conduta de alguém acabam numa prestação pública, e quando o agente sabe disso; assim como ocorre com o político no sucesso, com o fabricante no mercado, (...), e assim por diante"30.

$\mathrm{Na}$ contramão das práticas eugênicas dos nazistas, adquire relevância a ideologização do discurso axiológico sobre valores intrínsecos, sobre ética material, sobre naturalismo ético ou ética evolucionista, evidenciando argumentos de falácia naturalista. $\mathrm{O}$ desempenho equivocado do argumento falacioso consiste na conversão de um conceito em outro, com base em propriedades incomuns a ambos, o que configura um erro categorial. A falácia se evidencia pela inferência derivada desse simples erro. Exemplos clássicos de falácia naturalista na tradição alemã são a ética do mais alto e a ética do mais evoluído.

De acordo com Max Scheler (1874-1928), filósofo e axiólogo alemão, há uma fenomenologia do mais alto valor. Para o filósofo da ética material há, à moda da ordo amoris agostiniana, uma hierarquia de valores cujo acesso não é dado pelo entendimento, mas se nos torna perceptível mediante insights valorativos. Tal arrancada axiológica bate de frente com o conceito de valor de procedência econômica, o qual obedece às leis que regem a permuta dos bens no mercado. O objetivismo ético scheleriano contraria também frontalmente a ética weberiana. Enquanto o sociólogo se refere comumente a condutas de um agente que atua em espaços rarefeitos de orientação axiológica, a ética material do filósofo alemão repõe o agir numa

30 GEHLEN, A. Moral und Hypermoral. Eine pluralistische Ethik. 5. Aufl. Wiesbaden, 1986, p. 151. (Der Begriff der Verantwortung) "macht nur da einen deutlichen Sinn, wo jemand die Folgen seines Handelns öffentlich abgerechnet bekommt, und weiss; so der Politiker am Erfolg, der Fabrikant am Markt, der Beamte an der Kritik der Vorgesetzten, der Arbeiter an der Kontrolle der Leistung usw." 
zona onde imperam valores objetivos. Diferentemente do sociólogo Max Weber (1864-1920), a pessoa constitui em Scheler "exclusivelmente o último suporte de valores, mas não, e sob nenhuma hipótese, torna-se alguém que constitui valores" 31 .

Em sua obra-prima, $O$ formalismo na ética e a ética material (1916), o autor alemão parte do princípio de que há uma especificidade material nas intenções humanas, passível de ser rastreada nas cadeias fenomênicas de nossa vontade. Como o mundo, na condição de destinatário de nossas intenções, encontra-se estruturado por referências axiológicas, a intencionalidade humana "contém em si uma matéria de valores, anterior a qualquer experiência e independente do resultado de toda ação" 32 . O princípio fundacional da intencionalidade normativa redunda na eventual imputabilidade das ações, que não tem a ver com o fato de que alguém seja ou não responsável por isso ou aquilo, mas depende única e exclusivamente da essência axiológica da pessoa. Enquanto a responsabilidade por determinada conduta é caudatária de constelações circunstanciais e pode, eventualmente, inexistir (no caso de doenças psíquicas), a ausência da responsabilidade pessoal é, segundo Scheler, de todo impossível. À diferença do que ocorre com a imputação de determinados atos do agir, o conceito de responsabilidade moral tem, de acordo com o filósofo alemão, "suas raízes na vivência da própria pessoa e não se estrutura apenas em função de uma avaliação externa de suas ações". 33 A responsabilidade de um agente resulta, assim, não meramente do fato de ter violado leis morais ou transgredido normas sociais, mas reporta-se "ao saber imediato da própria autoria e sua relevância éticovalorativa: toda responsabilidade para com alguém (nossos semelhantes e Deus), quer dizer, qualquer responsabilidade relacional pressupõe a presença de co-responsabilidade consigo mesmo como vivência absoluta"34.

${ }^{31}$ SCHELER, M. Der Formalismus in der Ethik und die materiale Wertethik. Neuer Versuch der Grundlegung eines ethischen Personalismus. 3. Aufl. Halle: de Gruyter, p. 1927, p. 537. (...) ausschliesslich letzter Wertträger, nicht aber und in keinem Betracht Wertsetzer".

32 Ibidem, p. 160. "(...) eine von aller Erfahrung und allem Erfolge des Handelns unabhägige Materie von Werten in sich".

${ }^{33} \mathrm{Ibidem}$, p. 506. "I)m Erleben der Person selbst und ist nicht erst auf Grund einer äusseren Betrachtung ihrer Handlung gebildet".

${ }^{34}$ Ibidem, p. 507. "Alle Veratwortlichkeit 'vor' Jemand (Mensch, Gott), d.h. alle relative Verantwortlichkeit setzt dieses Erleben einer 'Selbstverantwortlichkeit' als absolutes Erlebnis voraus". 
$\mathrm{Na}$ medida em que Scheler reporta o agir responsável dos agentes sociais a um ethos coletivo, oriundo por sua vez de uma ordem cultural e religiosa abrangente de valores, ele tipifica a dependência das orientações morais de bens e objetivos que são alheios à ética. Tão-somente a relação de pertencer, como indivíduos, a um cosmo de conteúdos valorativos superindividuais assegura a unidade da comunidade social na recíproca complementação de auto-responsabilidade e co-responsabilidade. Scheler supera a distância entre a intencionalidade formal e as orientações materiais no âmbito do agir, ao deduzir o conjunto das ações humanas de uma dinâmica intencional, voltada para a realização de valores éticos que preexistem aos seres humanos e são necessariamente pressupostos para toda e qualquer tomada de posição ou escolha a ser feita pelos homens.

A posição de Scheler equivale a um holismo teleológico de responsabilidade, em que cabe ao homem a obrigação de agir moralmente, com base numa constelação metafísica que alberga em definitivo o ser humano. O filósofo alemão confere à ética material o estatuto incondicional de idéias blindadas contra toda e qualquer reflexão crítica e acaba estabelecendo uma hierarquia eterna de valores cujo acesso equivale à ontologização da experiência axiológica. A hierarquia de valores da ética material acaba reforçada, no fenomenólogo alemão, pela hierarquização biológica do homem no cosmos ${ }^{35}$.

Um objetivismo axiológico ainda mais extremado do que o scheleriano é defendido por Nicolai Hartmann (1882-1950), para quem o mundo real não chega sequer a ter influência sobre os valores, vale dizer, não são produto de preferências ou experimentação dentro do processo históricosocial. Pelo contrário, a história humana consiste em conhecer adequadamente o universo dos valores. Para Hartmann, as diferentes expressões da cultura revelam, ao longo dos séculos, a hegemonia de um par de valores sobre os demais; de resto, os valores são descobertos e não criados, suscetíveis de ordenação e hierarquia, à revelia das demais referências ontológicas do universo humano.

Em sua obra maior, Ética (1926), Hartmann explicita a ontológica objetivação do cosmo de valores. Paralelo a Scheler, ele passa da qualificação

${ }^{35}$ SCHELER. Die Stellung des Menschen im Kosmos. Darmstadt: Wissenschaftliche Buchgesellschaft, 1928. 
ética de ações à qualidade apriorística de valores conteudísticos que, imunes a juízos racionais, repousam "no sentimento que ampara a consciência de valor" 36 . A tarefa da filosofia consiste em trazer à luz a originariedade normativa do agir humano. "Ética filosófica", segundo Hartmann, "é maiêutica da consciência ética" ${ }^{37}$. Contrastivo a Scheler, a posição hartmanniana confere ao reino dos valores uma validade absoluta, inacessível ao conhecimento humano. A consciência ética expõe a metafísica dos valores, vale dizer, o universo ético "é evidentemente um auto-atuante poder no homem, não afetado por sua vontade", para apostrofar: "Trata-se realmente de ingerência de um poder 'superior', uma voz provinda de outro mundo - do mundo ideal dos valores”38. A ontologização axiológica deságua no subjetivismo voluntarista de uma liberdade com essência ético-real. "Retira alguém de mim a responsabilidade que tenho", observa Hartmann, "ele espezinha minha essência elementar como pessoa. Ele não nega alguma qualidade axiológica em mim (...), mas denega algo mais fundamental: o esteio, como tal, de possíveis qualidades éticas, a determinação originária do ser ético em mim"39. O realismo ontológico dos valores neutraliza, no ontólogo eticista, o conjunto dos processos intersubjetivos de fundamentação e interação cognitivas e perfaz, em suma, uma metafísica originária do ser normativo da espécie humana.

A ética do mais evoluído constrói-se, por sua vez, sobre o reducionismo da teoria de seleção natural e se distende interdisciplinarmente, como naturalismo ético, em múltiplas versões, tais como ética biológica, sociológica, psicológica, e assim por diante. O erro categorial de tomar matrizes descritivas, explicativas ou meramente formais como modelos próprios para inferir o que chamamos de bom ou correto implica admitir, por exemplo, que as leis científicas podem prescrever o suicídio, o estupro ou a calúnia, assim como podem propor a lealdade, o altruísmo ou a boa-fé. Em

36 HARTMANN, N. Ethik. 3. Aufl. Berlin: de Gruyter, 1949, p. 134. "Im Gefühl liegende(n) Wertbewusstsein".

${ }^{37}$ Ibidem, p. 29. "Philosophische Ethik ist Maieutik des sittlichen Bewusstseins".

38 Ibidem, p. 135. "(E)ine offenbar selbständige und selbsttätige Macht im Menschen, die seinem Willen entzogen ist. Es ist wirklich Einwirkung einer 'höheren' Macht, eine Stimme aus einer anderen Welt aus der idealen Welt der Werte".

${ }^{39} \mathrm{Ibidem}$, p. 732. "Nimmt mir jemand die Verantwortung ab, die ich trage, so vergeht er sich an meinem Grundwesen als Person. Er negiert nicht etwa bestimmte Wertqualitäten in mir (...), sondern er negiert etwas Fundamentaleres: den Träger möglicher sitlicher Qualitäten selbst, die Grundbedingungen sittlichen Seins in mir". 
ambos os casos, a lei que post factum explica o que não pôde deixar de ocorrer ou deixou necessariamente de acontecer torna-se idêntica à lei que justifica por que alguém fez isto ou deixou de fazer aquilo. Contrariamente ao que ocorre com a ética do mais alto, e a contrapelo dos clássicos argumentos do pensador inglês George E. Moore (1873-1958) ${ }^{40}$, a ética do mais evoluído continua em intensa efervescência categorial, tendo em vista as imbricações da teoria evolucionista com o utilitarismo clássico. Ou seja, a concepção darwiniana de natureza sugere que o fato natural de sobrevivência do mais apto (the fittest) decorra infalivelmente da constatação de que cada sobrevivente é também o melhor sobrevivente. Esse bem supremo é identificado por Charles R. Darwin (1809-1882) em termos de valores biológicos tais como o vigor e a saúde.

$\mathrm{Na}$ medida em que são significativos, tais componentes naturais do bem supremo provocam mais dissensão do que consenso. Já antes de Darwin, o apelo à natureza para uma escolha preferencial de bens carecia de um princípio ordenador que sustentasse o argumento da naturalidade de uma suposta hierarquia axiológica de bens naturais. "Depois de Darwin”, escreve H. Tristram Engelhardt (1941-), "o problema de identificar a natureza humana 'normativa' torna-se ainda mais agudo, não obstante a dificuldade elementar de saber como discernir entre a natureza humana verdadeira versus a pervertida tem desafiado sempre qualquer tentativa de providenciar uma lei natural para a ética" 41 .

Em suma, onde imperam processos despersonalizados, não há condições para aplicar uma matriz de condutas responsáveis. A lógica que rege dinâmicas anônimas não dá acesso a ações responsáveis. O que resta, à revelia do direito, é nivelar por baixo o badalado senso da responsabilidade.

\section{Considerações finais}

$\mathrm{Na}$ medida em que a concepção ética jonasiana reporta-se a Kant, as determinações categóricas deste assumem o caráter de referências ontológicas.

\footnotetext{
${ }^{40}$ MOORE, G. E. Principia Ethica. Cambridge: Cambridge University Press, 1993.

${ }^{41}$ ENGELHARDT. The Foundations of Christian Bioethics. Lisse, Netherlands: Swets \& Zeitlinger Publishers, 2000, p. 34. "After Darwin, the problem of identifying the 'normative' human nature becomes even more salient, although of fundamental difficulty of knowing how to discern true versus perverted human nature has always challenged any attempt at a natural law account of ethics."
} 
O que é moralmente bom, Jonas converte em valores intrínsecos que exigem plena realização. O que a doutrina ética jonasiana sustenta é a valoratividade do ser que, afetado pelo sentimento moral, configura e sustenta o fundamento das ações responsáveis. A expansão intrínseca de responsabilidade, na doutrina ética de Jonas, nada tem a ver com a dinâmica moderna, direcionada que está à ameaça apocalíptica da utopia tecnológica, valer dizer, $O$ Princípio Responsabilidade não é progressista e/ou revolucionário senão conservador e cético - em suma, zela pela heurística do medo à procura da fuga de uma ameaça definitiva.

O epíteto 'Responsabilidade para o Todo'42, o qual Jonas considera incondicionalmente verdadeiro para os problemas da humanidade não é o resultado de uma superação de problemas, mas a mera continuação do presente com o recurso de outros meios. $\mathrm{O}$ apelo à frugalidade e à ascese, ao respeito e à veneração, bem como o esforço de fazer da humanidade o sujeito de sua própria salvação são expressões de uma consciência com gestos derradeiros, terminantes de caráter metafísico. Responsabilidade e apocalipse dão-se as mãos em Jonas para inverter a filosofia da história moderna aos primórdios indeléveis da metafísica.

O caráter jonasiano de responsabilidade resulta da falta de limites que caracterizam a dinâmica do progresso, o qual aparentemente se move em direção ao fim do gênero humano, levado por uma incontrolável superposição de riscos mundo afora. $\mathrm{Na}$ esteira de Picht, os modelos metafísicos de Jonas são, com vistas à contingência histórica, bloqueados teoricamente por transcendência e alcançam a universalidade da moral praticamente apenas por transgressões e fracassos históricos. Por sua vez, a doutrina dos metafísicos Scheler e Hartmann, respeitadas suas diferenças teóricas, são incapazes de deduzir dos discursos ambientais a obrigatoriedade de zelar pela convivência sadia dos seres humanos.

Em suma, o que resta na contramão são formas simplistas de lidar com problemas complexos à luz de legitimações fundamentalistas, amparadas por responsabilidades avessas à imputação de deveres, e confiadas a operações metafísicas ao largo dos universos normativos da moral, da ética e do direito. A ameaça prevista não deriva da falta de obrigatoriedade ética para ações e

42 JONAS. Das Prinzip Verantwortung. Versuch einer Ethik für die technologische Zivilisation. Frankfurt a/Main: Suhrkamp, 1979, p. 72. 
condutas, próprias à compreensão e ao entendimento, mas resulta fidedignamente do processo de uma decomposição metafísica de valores teleológicos em direção a um intrínseco apocalipse in spe. 


\section{Referências}

APEL, K.-O. Auseinandersetzungen in Erprobung des transzendentalpragmatischen Ausatzes. Frankfurt a/Main: Suhrkamp, 1998.

BACON, F. Novum Organum sive indica vera de interpretatione naturae. In: The Latin Library, http://www.thelatinlibrary.com/bacon.html.

BECK, U. Was ist Globalisierung? Irrtümer des Globalismus - Antworten auf Globalisierung. Frankfurt a/Main: Suhrkamp, 1997.

BONHOEFFER, D. Ethik. Hg. Ilse Tödt, Heinz Eduard, Ernst Feil und Clifford Green. München, 1992.

BURSZTYN, M. (org.). Ciência, Ética e Sustentabilidade: desafios ao novo século. São Paulo: Cortez Editora, 2006.

CHWASZCZA, C. Praktische Vernunft als vernünftige Práxis. Ein Grundriss. Weilerswist: Verlbrück Wissenschaft, 2003.

DESCARTES, R. Discours de la Méthode. Hamburg: F. Meiner (Französisch Deutsch), 1990.

GEHLEN, A. Moral und Hypermoral. Eine pluralistische Ethik. 5. Aufl. Wiesbaden, 1986.

GIACOIA Jr., O. "Um Direito próprio da Natureza? Notas sobre Ética, Direito e Tecnologia”. In Fragmentos de Cultura, Goiânia, v. 14, n. 4, 2004, p. 637-654.

ENGELHARDT, T. The Foundations of Christian Bioethics. Lisse, Netherlands: Swets \& Zeitlinger Publishers, 2000.

HABERMAS, J. O Futuro da Natureza Humana. A caminho de uma eugenia liberal? Trad. Do alemão por Karina Jannini. São Paulo: Martins Fontes, 2004.

HARTMANN, N. Ethik. 3. Aufl. Berlin: de Gruyter, 1949.

HASTEDT, H. Aufklãrung und Technik. Grundprobleme einer Ethik der Technik. Frankfurt a/M: Suhrkamp, 1991.

JONAS, H. Das Prinzip Verantwortung. Versuch einer Ethik für die technologische Zivilisation. Frankfurt a/Main: Suhrkamp, 1979.

Technik, Medizin und Eugenik. Praxis des Prinzips Verantwortung Frankfurt a/Main: Insel Verlag, 1985.

- Organismus und Freiheit: Ansätze zu einer philosophischen Biologie. Göttingen, 1973.

. "Por que a técnica moderna é um objeto para a ética”. Tradução Oswaldo

Giacoia Jr. In Natureza Humana: Revista Internacional de Filosofia e Práticas Psicoterápicas. São Paulo, v. 1, n. 2, 1999, p. 407-420. 
LUDGER, H. "Grundprobleme der gegenwärtigen Verantwortungsdiskussion". In: Information Philosophie, Heft 3, p. 18-31, 2007.

MOORE, G. E. Principia Ethica. Cambridge: Cambridge University Press, 1993.

MÜLLER, W. E. Der Begriff der Verantwortung bei Hans Jonas. Frankfurt a/Main: Suhrkamp, 2008.

OTTO, R. "Das Gefühl der Verantwortlichkeit”. In: Aufsätze zur Ethik. Hg. Jack Stewart Boozer. München 1981.

PICHT, G. “Der Begriff der Verantwortung”. In: Wahrheit, Vernunft, Verantwortung. Philoso- phische Studien. Stuttgart, 1969.

POTTER, J. Bioethics: Bridge to the Future. Englewood Cliffs, N.J.: Prentice-Hall 1971.

SANTOS, R. dos. "O problema da técnica e a crítica à tradição na ética de Hans Jonas". In Dissertatio, Revista do Departamento de Filosofia da UFPel. Pelotas, $\mathrm{n}^{\circ} 30$, p. 269-291.

SCHELER, M. Der Formalismus in der Ethik und die materiale Wertethik. Neuer Versuch der Grundlegung eines ethischen Personalismus. 3. Aufl, Halle: Gerhard Verlag, 1916.

SCHWEITZER, A. Kultur und Ethik. Kulturphilosophie, 6. Aufl., München: 1947.

VIDOTTE BLANCO TARREGA, M. Cr. \& GOMES DE OLIVEIRA, B. "Responsabilidade corporativa, Meio ambiente e Desenvolvimento sustentável". In: VIDOTTE BLANCO TARREGA, Maria Cristina. Direito Ambiental e Desenvolvimento Sustentável. São Paulo: RCS Editora, 2007.

E-mail: heck@pesquisador.cnpq.br

Recebido em: Setembro/2010 Aprovado em: Outubro/2010 